\title{
Academy of Science of South Africa launches a mapping survey of life science research and diagnostic activity in South Africa
}

To the Editor: The Academy of Science of South Africa (ASSAf) has announced a research initiative to assess life science activity in South Africa (SA). One aspect of the study being undertaken by the ASSAf Panel on Biosafety and Biosecurity is an online survey whereby ASSAf aims to identify and map research and diagnostic facilities engaged in life science activities in the country.

The results of this mapping survey will provide a clear and up-to-date understanding of the current distribution and focus of the life sciences in SA and facilitate their future research and development. The mapping will also inform a more detailed survey to be undertaken later this year. Via this survey and other research, the Panel will assess the state of biosafety and biosecurity practices and the application of ethics in the life sciences throughout SA. Such studies will include an empirical evaluation of practices, as well as a critical assessment of current legislation at national and institutional level. These data will not only contribute towards understanding life science undertakings in the country, but also provide valuable tools for the continuing dialogue between scientists and policymakers.

To ensure that the initial mapping survey is as widely distributed as possible, ASSAf appeals to heads of diagnostic laboratories, research facilities, university departments and private colleges to undertake a 5-minute survey that is available online (http://www.surveymonkey. $\mathrm{com} / \mathrm{s} / \mathrm{CB} 6 \mathrm{JP} 65)$, and also to promote the survey as widely as possible.

The survey focuses on basic information pertaining to laboratorybased life science research and diagnostics in these facilities. The results of the survey will form a database that will be securely stored at ASSAf, and will not be distributed to any third party for commercial gain.

As the official national science academy of South Africa, ASSAf strives to provide evidence-based scientific advice to the South African scientific and policy community. A better understanding of all life science research undertaken in the country, and the distribution of life science researchers, will be invaluable for future scientific research and development.

\section{Bezuidenhout}

Academy of Science of South Africa, Pretoria, South Africa

Louiseb@assaf.org.za

\section{Gould}

Institute for Security Studies, Pretoria, South Africa

\section{J Farrant}

Department of Molecular and Cellular Biology, University of Cape Town, South Africa

S Afr Med J 2013;103(7):437. DOI:10.7196/SAMJ.7025 